Polymer Journal, Vol. 39, No. 3, pp. 239-244 (2007)

(C) 2007 The Society of Polymer Science, Japan

\title{
Lipase-Catalyzed Selective Synthesis and Micellization of Poly(ethylene glycol)-block-poly( $\varepsilon$-caprolactone) Copolymer Possessing a Carboxylic Acid Group at the PEG Chain End
}

\author{
Motoi OISHI, ${ }^{1,2}$ Satoshi IKEO, ${ }^{2}$ and Yukio NAGASAKI ${ }^{1,2, \dagger}$ \\ ${ }^{1}$ Tsukuba Research Center for Interdisciplinary Materials Science (TIMS), University of Tsukuba, \\ 1-1-1 Ten-noudai, Tsukuba 305-8573, Japan \\ ${ }^{2}$ Institute of Materials Science, University of Tsukuba, 1-1-1 Ten-noudai, Tsukuba 305-8573, Japan
}

(Received November 27, 2006; Accepted December 15, 2006; Published February 2, 2007)

\begin{abstract}
A novel poly(ethylene glycol)-block-poly( $\varepsilon$-caprolactone) (PEG- $b$-PCL) copolymer possessing a carboxylic acid group at the PEG chain end was prepared by the one-pot lipase-catalyzed polymerization of $\varepsilon$-CL using an $\alpha$-carboxylic acid- $\omega$-hydroxy-PEG as a macroinitiator. This synthetic approach is remarkable because it dose not require tedious chemical routes such as end-functional group changing steps and protection-deprotection steps. The PEG- $b$-PCL copolymer spontaneously forms a polymeric micelle with a size of $35.3 \mathrm{~nm}$ and a narrow polydispersity index $\left(\mu_{2} / \Gamma^{2}=0.15\right)$ in aqueous media. Furthermore, the PEG- $b$-PCL micelles had a negative zeta potential due to the existence of the reactive carboxylic acid groups on the surface of the PEG- $b$-PCL micelles, indicating that the carboxylic acid end-functionalized PEG- $b$-PCL copolymer was successfully prepared. Therefore, this reactive PEG- $b$-PCL micelle may have potential uses in the field of drug delivery systems as a targetable drug carrier.

[doi:10.1295/polymj.PJ2006172]

KEY WORDS Lipase / Poly(ethylene glycol)-poly(e-caprolactone) Block Copolymer / EndFunctionalization / Reactive Polymeric Micelle / Drug Delivery System /
\end{abstract}

Polymeric micelles formed in aqueous media through the self-assembly of block copolymers composed of a hydrophobic-hydrophilic segment have attracted considerable attention in fundamental and applied fields. ${ }^{1}$ One of the extensive studies done in these applied fields is related to drug delivery systems (DDSs) based on polymeric micelles from poly(ethylene glycol)-block-poly( $\varepsilon$-caprolactone) copolymers (PEG- $b$-PCL), since the PEG- $b$-PCL micelles bearing FDA-approved polymer components ${ }^{2}$ showed excellent biocompatibility, nontoxicity, high drug-loading capacity, long circulation time in the bloodstream, and high biodegrability. ${ }^{3}$ Furthermore, the installation of specific ligand molecules on the surface of PEG- $b$ PCL micelles is indispensable to the achievement of specific and enhanced cellular uptake at the target tissue, allowing the effective dose and side effects of the drugs to be reduced. Thus, ligand-installed PEG- $b$ PCL micelles are a promising approach to constructing targetable drug carriers.

A major key to the successful development of targetable drug carriers is considered to be the preparation of an end-functionalized PEG- $b$-PCL copolymer that allows easy installation of ligand molecules in the reactive group located at the PEG chain end. One of the practical methods for preparing PEG- $b$ PCL copolymers is the ring-opening polymerization of $\varepsilon$-CL in the presence of a PEG-OH macroinitiator catalyzed by a metallic complex (stannous octoate). ${ }^{4}$ However, the resulting PEG- $b$-PCL copolymers synthesized so far lack a reactive group at the PEG end, and furthermore the metallic complex must be completely removed, especially in medical applications. To prepare the end-functionalized PEG- $b$-PCL copolymers, the introduction of reactive groups into the PEG chain end may be accomplished by the use of an R-PEG-OH macroinitiator bearing an inert and/or protected functional group (R) for polymerization, followed by the conversion of the inert and/or protected functional group into a highly reactive functional group. The conversion of the functional end group in the block copolymer system, however, often causes troubles such as side reactions, low conversion efficiencies, etc. Thus, one-pot synthesis seems to be the most promising for the preparation of end-functionalized block copolymers without any deprotection step.

A unique finding, which we would like to describe here, is a novel synthetic approach to carboxylic acid end-functionalized PEG- $b$-PCL copolymer by means of the one-pot lipase-catalyzed polymerization ${ }^{5}$ of $\varepsilon$ $\mathrm{CL}$ using an $\alpha$-carboxylic acid- $\omega$-hydroxy-PEG as a macroinitiator, which enables the formation of reactive PEG- $b$-PCL micelles as potential targetable drug carriers. The benefit of using a heterobifunctional PEG and lipase as a macroinitiator and catalyst, re-

${ }^{\dagger}$ To whom correspondence should be addressed (Tel/Fax: +81-29-853-5749, E-mail: nagasaki@nagalabo.jp). 
spectively, is that tedious production steps, such as end-functional group changes and protection-deprotection, are unnecessary.

\section{EXPERIMENTAL}

\section{Materials}

Tetrahydrofuran (THF) (Kanto Chemical), toluene (Kanto Chemical), triethylamine (Kanto Chemical), ethylene oxide (Sumitomo Seika), 2,2,5,5-tetramethyl-2,5-disila-1-azacyclopentane (TDA) (GELEST, Inc.), succinic anhydride (Wako), and $\varepsilon$-caprolactone $(\varepsilon$-CL) (Kanto Chemical) were purified by conventional methods. Methanol, 2-propanol, and dichloromethane were purchased from Kanto Chemical and used without further purification. Novozyme-435 (10 units/mg, immobilized lipase B from Candida antarctica) was purchased from Sigma. Potassium naphthalene was used as a THF solution, whose concentration was determined by titration. Water was purified using a Milli-Q instrument (MILLIPORE).

\section{Polymer Analysis}

${ }^{1} \mathrm{H}$ NMR $(600 \mathrm{MHz})$ spectra were obtained in $\mathrm{CDCl}_{3}$ using a Bruker AVANCE-600 spectrometer. Chemical shifts were reported in ppm relative to $\mathrm{CDCl}_{3}\left(\delta 7.26,{ }^{1} \mathrm{H}\right)$. Size exclusion chromatography (SEC) was performed using a TOSO HLC-8020 equipped with an internal refractive index (RI) detector (RID-6A) with a combination of TSK G3000 ${ }_{\mathrm{HR}}$ and $\mathrm{G} 2500_{\mathrm{HR}}$ columns using THF as an eluent.

\section{Preparation of $\alpha$-Amino- $\omega$-hydroxy-PEG $\left(\mathrm{H}_{2} \mathrm{~N}-\mathrm{PEG}\right.$ - $\mathrm{OH})$}

To a solution of TDA $(0.159 \mathrm{~g}, 1.0 \mathrm{mmol})$ in THF $(25 \mathrm{~mL})$, potassium naphthalene solution $(0.357 \mathrm{~mol} /$ $\mathrm{L}$ in THF, $2.8 \mathrm{~mL}, 1.0 \mathrm{mmol}$ ) was added at room temperature under a nitrogen atmosphere. After stirring for $10 \mathrm{~min}$, condensed ethylene oxide $(5.7 \mathrm{~mL}$, $114 \mathrm{mmol}$ ) was added via a cooled syringe to the initiator solution, and the reaction mixture was stirred in a water bath for $2 \mathrm{~d}$. After the polymerization, acidic methanol $(10 \mathrm{~mL})$ was added to the polymer solution to obtain the $\mathrm{H}_{2} \mathrm{~N}-\mathrm{PEG}-\mathrm{OH}$ (deprotection of the TDA). The polymer was recovered by precipitation into cold 2-propanol $\left(-15^{\circ} \mathrm{C}, 2 \mathrm{~L}\right)$, centrifuged for $30 \mathrm{~min}$ at $6000 \mathrm{rpm}$ and then freeze-dried to obtain $\mathrm{H}_{2} \mathrm{~N}$-PEG-OH $(4.61 \mathrm{~g}, 92 \%$ yield). The molecular weight $\left(M_{\mathrm{n}}\right)$ and polydispersity $\left(M_{\mathrm{w}} / M_{\mathrm{n}}\right)$ were determined by means of SEC chromatography though the exact $M_{\mathrm{n}}$ might not be obtained due to the adsorption of the amino group on the SEC column. SEC $M_{\mathrm{n}}=4400, M_{\mathrm{w}} / M_{\mathrm{n}}=1.4$ (calculated $\left.M_{\mathrm{n}}=5100\right)$; ${ }^{1} \mathrm{H}$ NMR $\left(\mathrm{CDCl}_{3}\right) \delta 2.86\left(\mathrm{t}, J=7.1 \mathrm{~Hz}, 2 \mathrm{H}, \mathrm{H}_{2} \mathrm{~N}-\right.$ $\mathrm{CH}_{2} \mathrm{CH}_{2}-\mathrm{O}-$ ), 3.71 (s, 696H, PEG backbone).
Preparation of $\alpha$-Carboxylic acid- $\omega$-hydroxy-PEG (HOOC-PEG-OH)

A solution of succinic anhydride in THF $(255 \mu \mathrm{L}$, $179 \mu \mathrm{mol}, 0.7 \mathrm{M}$ ), was added to a mixture of $\mathrm{H}_{2} \mathrm{~N}$ PEG-OH $(1.00 \mathrm{~g}, 149 \mu \mathrm{mol})$ and triethylamine $(17.9$ $\mathrm{mg}, 179 \mu \mathrm{mol})$ in THF $(20 \mathrm{~mL})$, and the reaction mixture was stirred at room temperature for $9 \mathrm{~h}$. The polymer was recovered by precipitation into cold 2-propanol $\left(-15^{\circ} \mathrm{C}, 200 \mathrm{~mL}\right)$, centrifuged for $45 \mathrm{~min}$ at $6000 \mathrm{rpm}$ and then freeze-dried to obtain HOOCPEG-OH $\left(0.977 \mathrm{~g}, 97 \%\right.$ yield). SEC $M_{\mathrm{n}}=6300$, $M_{\mathrm{w}} / M_{\mathrm{n}}=1.3 \quad$ (calculated $\left.M_{\mathrm{n}}=5200\right) ;{ }^{1} \mathrm{H}$ NMR $\left(\mathrm{CDCl}_{3}\right) \delta 2.52\left(\mathrm{t}, J=6.8 \mathrm{~Hz}, 2 \mathrm{H}, \mathrm{HOOC}-\mathrm{CH}_{2}-\right.$ $\mathrm{CH}_{2}-\mathrm{CONH}-$ ), 2.64 (t, $J=6.8 \mathrm{~Hz}, 2 \mathrm{H}, \mathrm{HOOC}-\mathrm{CH}_{2}-$ $\mathrm{CH}_{2}$-CONH-), 3.71 (s, 573H, PEG backbone).

Preparation of Carboxylic Acid End-Functionalized PEG-b-PCL Copolymer

To a solution of HOOC-PEG-OH $(0.491 \mathrm{~g}, 78$ $\mu \mathrm{mol})$ and Novozyme-435 $(100 \mathrm{mg})$ in toluene $(10$ $\mathrm{mL}), \varepsilon$-CL $(1.141 \mathrm{~g}, 10 \mathrm{mmol}, 128$ eq.) was added, and polymerization was carried out at $60^{\circ} \mathrm{C}$ for $24 \mathrm{~h}$. The resulting polymers were dissolved in dichloromethane and filtered to remove the Novozyme- 435 . The block polymer was recovered by precipitation into cold methanol as a poor solvent $\left(-4{ }^{\circ} \mathrm{C}, 500 \mathrm{~mL}\right)$ and centrifuged for $30 \mathrm{~min}$ at $6000 \mathrm{rpm}$. To remove the remaining HOOC-PEG-OH (pre-polymer), further purification was carried out by precipitation of the HOOC-PEG-OH into cold 2-propanol $\left(-15^{\circ} \mathrm{C}, 500\right.$ $\mathrm{mL}$ ) and centrifugation for $30 \mathrm{~min}$ at $6000 \mathrm{rpm}$. The soluble part was evaporated and then freeze-dried to obtain carboxylic acid end-functionalized PEG- $b$ PCL copolymer (64 mg, $4 \%$ yield). The molecular weight $\left(M_{\mathrm{n}}\right)$ and polydispersity $\left(M_{\mathrm{w}} / M_{\mathrm{n}}\right)$ were determined by means of SEC chromatography, though the exact $M_{\mathrm{n}}$ might not be obtained due to the adsorption of the block copolymer on the SEC column. SEC $M_{\mathrm{n}}=16000, M_{\mathrm{w}} / M_{\mathrm{n}}=1.6 ;{ }^{1} \mathrm{H}$ NMR $\left(\mathrm{CDCl}_{3}\right)$ $\delta 1.36\left(\mathrm{~s}, \quad 520 \mathrm{H},-\mathrm{CO}-\mathrm{CH}_{2} \mathrm{CH}_{2} \mathrm{CH}_{2} \mathrm{CH}_{2} \mathrm{CH}_{2}-\mathrm{O}-\right)$, 1.62 (s, $1040 \mathrm{H}$, - $\mathrm{CO}-\mathrm{CH}_{2} \mathrm{CH}_{2} \mathrm{CH}_{2} \mathrm{CH}_{2} \mathrm{CH}_{2}-\mathrm{O}-$ ), 2.31 (s, $520 \mathrm{H}$, - $\mathrm{CO}-\mathrm{CH}_{2} \mathrm{CH}_{2} \mathrm{CH}_{2} \mathrm{CH}_{2} \mathrm{CH}_{2}-\mathrm{O}-$ ), 3.71 (s, $573 \mathrm{H}$, PEG backbone), 4.17 (s, $520 \mathrm{H}$, - $\mathrm{CO}-\mathrm{CH}_{2} \mathrm{CH}_{2}-$ $\mathrm{CH}_{2} \mathrm{CH}_{2} \mathrm{CH}_{2}$-O-).

\section{Preparation and DLS Measurement of the PEG- $b$ - PCL Micelles}

To $10 \mathrm{~mL}$ of deionized water, a solution of PEG- $b$ PCL copolymer $(10 \mathrm{mg})$ in acetone $(1 \mathrm{~mL})$ was added dropwise, followed by adjustment of the $\mathrm{pH}$ to 2.0 , 3.5, 4.5, 5.0, 7.4 and 9.2. A light-scattering spectrometer (DLS-7000, Photal, Otsuka Electronics) equipped with a $75 \mathrm{~mW}$ Ar-laser that produces a vertically polarized incident beam at $\lambda_{0}=488 \mathrm{~nm}$ was used in the present study for the DLS measurements. During 


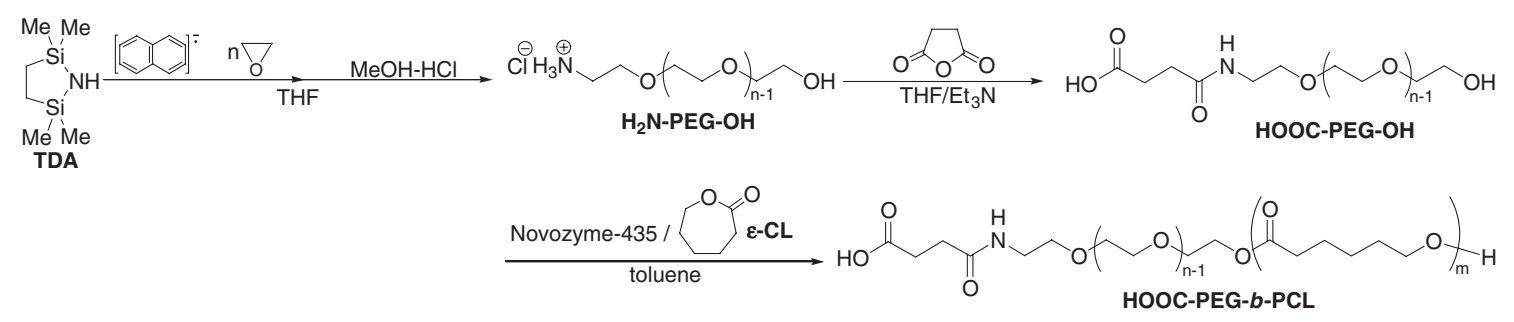

Scheme 1. Synthetic route to carboxylic acid end-functionalized PEG- $b$-PCL copolymer.

the DLS measurements, the autocorrelation function was analyzed using the cumulant method, in which

$g^{(1)}(\tau)=\exp \left[-\bar{\Gamma} \tau+\left(\mu_{2} / 2\right) \tau^{2}-\left(\mu_{3} / 3 !\right) \tau^{3}+\cdots\right](1)$

yielding an average characteristic line width of $\bar{\Gamma}$. The $\mathrm{z}$-averaged diffusion coefficient was obtained from the $\bar{\Gamma}$ based on the following equations:

$$
\begin{aligned}
\bar{\Gamma} & =D q^{2} \\
q & =(4 \pi n / \lambda) \sin (\theta / 2)
\end{aligned}
$$

where $q$ is the magnitude of the scattering vector, $n$ is the refractive index of the solvent, and $\theta$ is the detection angle. The hydrodynamic radius, $d$, can then be calculated using the Stokes-Einstein equation:

$$
d=k_{\mathrm{B}} T /(6 \pi \eta D)
$$

where $k_{\mathrm{B}}$ is the Boltzmann constant, $T$ is the absolute temperature, and $\eta$ is the viscosity of the solvent. Also, the polydispersity index $\left(\mathrm{PDI}=\mu_{2} / \Gamma^{2}\right)$ was derived from eq 1 .

Zeta Potential Measurement of the PEG-b-PCL Micelles

Lasser-Doppler electrophoresis measurements of the PEG- $b$-PCL micelles were carried out under various $\mathrm{pH}$ conditions ( $\mathrm{pH} 2.1,3.6,4.4,4.8,7.2$ and 9.1) (ELS-600, Photal, Otsuka Electronics). From the determined electrophoretic mobility, the zeta-potential $(\zeta)$ was calculated according to the Smoluchouski equation, as follows:

$$
\zeta=4 \pi n \eta \mu u / \varepsilon
$$

where $\eta$ is the viscosity of the solution, $u$ is the electrophoretic mobility, and $\varepsilon$ is the dielectric constant of the solvent.

\section{RESULTS AND DISCUSSION}

A synthetic route to the carboxylic acid endfunctionalized PEG- $b$-PCL copolymer is shown in Scheme 1. A heterobifunctional PEG bearing a carboxylic acid group at the $\alpha$-end and a hydroxyl group at the $\omega$-end (HOOC-PEG-OH) was successfully prepared, and thus the anionic ring-opening polymeriza-

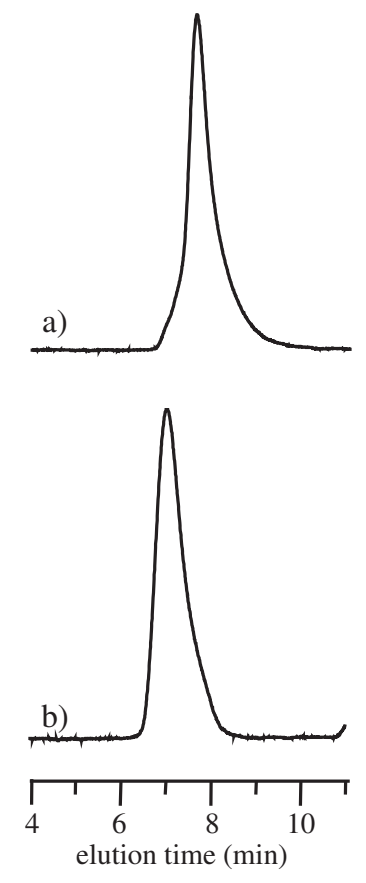

Figure 1. SEC chromatograms of a) HOOC-PEG-OH b) purified PEG- $b$-PCL copolymer.

tion of ethylene oxide with the 2,2,5,5-tetramethyl2,5-disila-1-azacyclopentane (TDA)/potassium naphthalene system quantitatively afforded $\mathrm{H}_{2} \mathrm{~N}$-PEG$\mathrm{OH}^{6}{ }^{6}$ which was in turn converted into the HOOCPEG-OH by treatment with 1.2 equivalents of succinic anhydride. According to the SEC analysis (Figure 1a), the molecular weight and polydispersity of the HOOC-PEG-OH were found to be $M_{\mathrm{n}}=6300$ and $M_{\mathrm{w}} / M_{\mathrm{n}}=1.3$, respectively, which agrees fairly well with the calculated value (calculated $M_{\mathrm{n}}=5200$ ). A ${ }^{1} \mathrm{H}$ NMR spectrum of HOOC-PEG-OH is shown in Figure 2a with assignments, where ethylene protons between the two carbonyl groups were observed at around $2.5 \mathrm{ppm}$ (HOOC- $\mathrm{CH}_{\mathbf{2}} \mathrm{CH}_{2}-\mathrm{CONH}-$ ), along with a markedly diminished methylene peak at $2.86 \mathrm{ppm}\left(\mathrm{H}_{2} \mathrm{~N}-\mathrm{CH}_{2}-\mathrm{CH}_{2}-\mathrm{O}-\right)$ attributed to the $\mathrm{H}_{2} \mathrm{~N}$ PEG-OH. In addition, ethylene protons corresponding to the succinate ester group at around $2.3 \mathrm{ppm}$ (-OCO$\left.\mathrm{CH}_{2} \mathrm{CH}_{2}-\mathrm{COOH}\right)^{7}$ formed through the reaction with succinic anhydride and hydroxyl group at the PEG $\omega$-end were not observed, indicating that succinic an- 


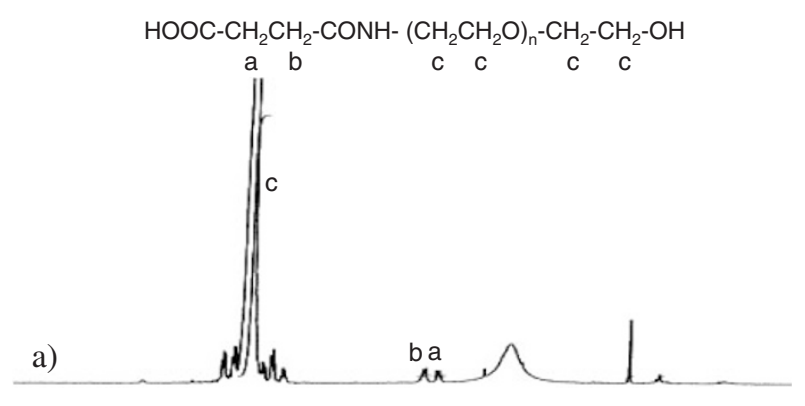

HOOC- $\mathrm{CH}_{2} \mathrm{CH}_{2}-\mathrm{CONH}-\left(\mathrm{CH}_{2} \mathrm{CH}_{2} \mathrm{O}\right)_{\mathrm{n} 2}-\left(\mathrm{CO}-\mathrm{CH}_{2} \mathrm{CH}_{2} \mathrm{CH}_{2} \mathrm{CH}_{2} \mathrm{CH}_{2}-\mathrm{O}-\right)_{\mathrm{m}}-\mathrm{H}$

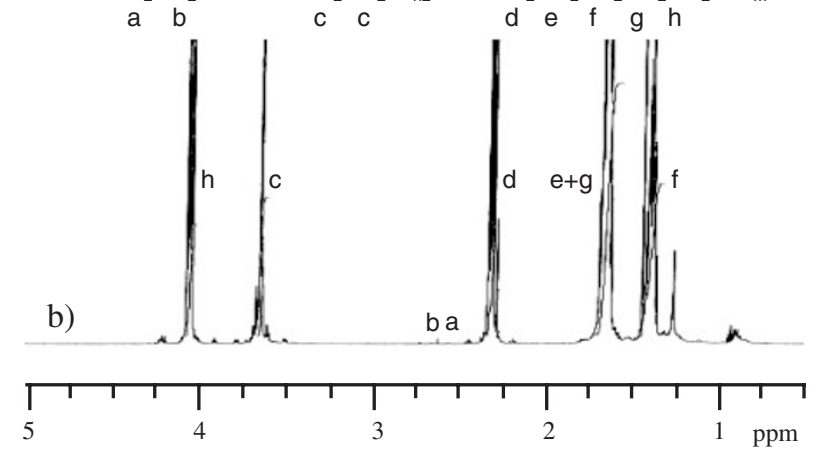

Figure 2. ${ }^{1} \mathrm{H}$ NMR spectra of a) HOOC-PEG-OH and b) purified PEG- $b$-PCL copolymer in $\mathrm{CDCl}_{3}$.

hydride was selectively reacted with the amino group of the $\mathrm{H}_{2} \mathrm{~N}$-PEG-OH. The degree of functionality of the carboxylic acid was determined to be $>94.5 \%$ based on the integral ratio between the PEG backbone protons (3.7 ppm - $\left.\mathrm{OCH}_{2} \mathrm{CH}_{2^{-}}\right)$and the ethylene protons of the succinate carbonyl moiety (2.52 and $2.64 \mathrm{ppm}, \mathrm{HOOC}-\mathrm{CH}_{\mathbf{2}} \mathrm{CH}_{2}-\mathrm{CONH}-$ ).

The ring-opening lipase-catalyzed (Novozyme-435: immobilized lipase B from Candida antarctica) polymerization of $\varepsilon$-CL in the presence of the HOOCPEG-OH macroinitiator was carried out at $60^{\circ} \mathrm{C}$ in toluene for $24 \mathrm{~h}$ with an $\varepsilon$-CL-to-HOOC-PEG-OH molar ratio of 128 ([ $\varepsilon$-CL $] /[$ HOOC-PEG-OH $]=$ 128). The polymerization smoothly proceeded with complete consumption of the $\varepsilon$-CL within $6 \mathrm{~h}(100 \%$ conversion), but yield (4\%) of purified HOOC-PEGb-PCL copolymer was found to be low due to loss of the copolymer during the repeating precipitation process, low conversion of the HOOC-PEG-OH macroinitiator $(<30 \%$ conversion), and the formation of large amount homo-oligoCL initiated by trace amounts of water in the polymerization system. ${ }^{8}$ Figures $1 b$ and $2 b$ show the SEC chromatogram and ${ }^{1} \mathrm{H}$ NMR spectrum of the purified PEG- $b$-PCL copolymer with assignments, respectively. As seen in the SEC chromatograms (Figure 1b), the PEG- $b$ PCL copolymer $\left(M_{\mathrm{n}}=16000, M_{\mathrm{w}} / M_{\mathrm{n}}=1.6\right)$ gave a unimodal peak at a higher-molecular-weight position (i.e., shorter elution time) compared to the HOOCPEG-OH $\quad\left(M_{\mathrm{n}}=6300, M_{\mathrm{w}} / M_{\mathrm{n}}=1.3\right.$, Figure 1a). Note that the unreacted HOOC-PEG-OH and homo-
oligoCL were not observed in the SEC chromatogram of the PEG- $b$-PCL copolymer. In the ${ }^{1} \mathrm{H}$ NMR spectrum (Figure $2 \mathrm{~b}$ ), the peaks corresponding to both of the PEG and the PCL segments were clearly observed, which is consistent with the formation of a block copolymer. Based on the integral ratio between the PEG backbone protons $\left(3.7 \mathrm{ppm}-\mathrm{OCH}_{\mathbf{2}} \mathrm{CH}_{2^{-}}\right.$) and the methylene protons of the PCL segment $(4.17 \mathrm{ppm}$, - $\mathrm{CO}-\mathrm{CH}_{2} \mathrm{CH}_{2} \mathrm{CH}_{2} \mathrm{CH}_{2} \mathrm{CH}_{2}$-O-), the DP of the PCL segment and the molecular weight of the block copolymer were calculated to be 260 and 32300 , respectively. Although the molecular weight calculated from ${ }^{1} \mathrm{H}$ NMR spectrum in Figure $2 \mathrm{~b}$ does not agree with the molecular weight calculated from the SEC analysis (Figure 1b), since the PEG- $b$-PCL copolymer tends to appear on the lower-molecular-weight position in the SEC analysis, presumably due to adsorption of the block copolymer on the gel in SEC column. Furthermore, it is difficult to estimate the degree of functionality of the carboxylic acid in the PEG- $b$ PCL copolymer from the peaks corresponding to the terminal two methylene moieties at $\delta 2.52$ and $2.64 \mathrm{ppm}$ in the ${ }^{1} \mathrm{H}$ NMR spectrum.

To clarify the presence of the carboxylic acid at the PEG chain end of the block copolymer, the surface charge of the PEG- $b$-PCL copolymer micelles was evaluated by means of zeta potential $(\zeta)$ measurement under various $\mathrm{pH}$ conditions. The size and polydispersity index of the PEG- $b$-PCL copolymer micelles thus prepared were estimated by means of DLS measurement at $\mathrm{pH} 7.4$. The PEG- $b$-PCL micelle $(1.0 \mathrm{mg} /$ $\mathrm{mL}$ ) had an average hydrodynamic diameter of $35.3 \mathrm{~nm}$ with a relatively narrow polydispersity index $\left(\mu_{2} / \Gamma^{2}\right)$ of 0.15 , showing a unimodal distribution, as shown in Figure 3. In addition, the size of the micelles was independent on the polymer concentration (2.0 $\mathrm{mg} / \mathrm{mL}: 40.2 \mathrm{~nm}, 0.2 \mathrm{mg} / \mathrm{mL}: 38.1 \mathrm{~nm})$. The size of the prepared PEG- $b$-PCL micelles were almost consistent with the reported values, ${ }^{3}$ indicating the forma-

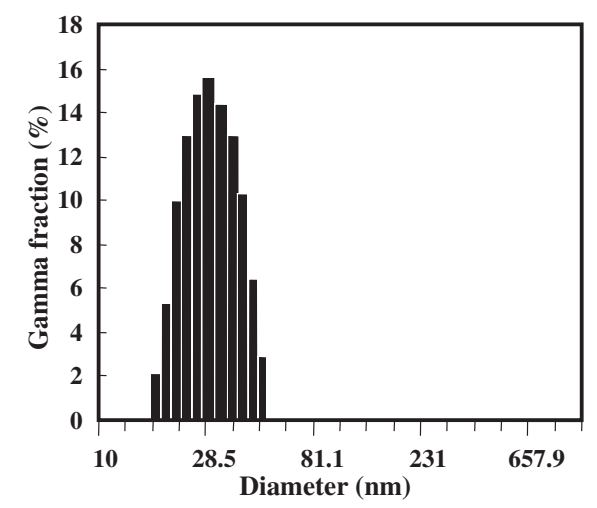

Figure 3. Size distribution of PEG- $b$-PCL micelles obtained by the histographic analysis of the DLS measurement (detection angle, $90^{\circ}$; temperature, $37^{\circ} \mathrm{C} ; \mathrm{pH}, 7.4$ ). 


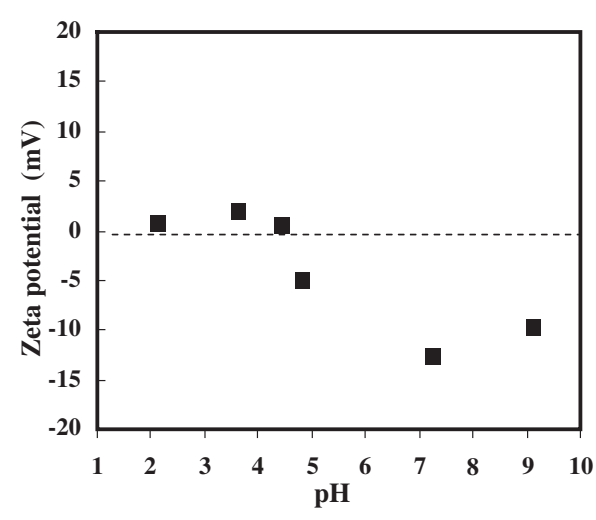

Figure 4. Zeta potential measurement of PEG- $b$-PCL micelles at various $\mathrm{pH}$ values $(2.1,3.6,4.4,4.8,7.2$ and 9.1).

tion of core-shell type of micelle structure. As can be seen in Figure 4, the PEG- $b$-PCL micelles had a negative value of the zeta potential, $\zeta=-14 \mathrm{mV}$, at $\mathrm{pH}$ 7.2. Note that the existence of carboxylic acid groups on the surface of the PEG- $b$-PCL micelles obviously contributed to this negative value, since most of the carboxylic acid groups should be in dissociated form $\left(-\mathrm{COO}^{-}\right)$at $\mathrm{pH}$ 7.2. Concomitantly, as the $\mathrm{pH}$ decreased, the zeta potential of the PEG- $b$-PCL micelles shifted from negative values $(\zeta<0)$ to zero $(\zeta \sim 0)$ due to the protonation of the carboxylic acid groups $(-\mathrm{COOH})$ on the surface of PEG- $b$-PCL micelles. It should also be observed that these zeta potential values for the changes in $\mathrm{pH}$ are indeed close to the $\mathrm{p} K_{\mathrm{a}}$ value of carboxylic acid $(\sim 5)$, strongly suggesting the formation of a carboxylic acid endfunctionalized PEG- $b$-PCL copolymer.
The lipase-catalyzed polymerizations of lactones involving $\varepsilon$-CL are considered to proceed through an acyl-enzyme intermediate, and a plausible polymerization mechanism is shown in Scheme 2. ${ }^{9}$ The catalytic site of the lipase is known to be a hydroxyl group of the serine residue, which reacts with $\varepsilon$-CL to give the acyl-enzyme intermediate (enzyme-activated monomer, EM); viz., the key step is the formation of the EM. The initiation is the nucleophilic attack of the EM acyl carbon by the hydroxyl group of the HOOC-PEG-OH to form HOOC-PEG-O-CO- $\left(\mathrm{CH}_{2}\right)_{5}-$ $\mathrm{OH}$ as the propagation species. In the propagation step, the EM is nucleophilically attacked by the terminal hydroxyl group of the propagating polymer. The kinetics of the polymerization showed that the ratedetermining step is the formation of the EM, indicating that polymerization presumably proceeds through a monomer-activated mechanism. In this mechanism, Panova and Kaplan reported that the lipase-catalyzed polymerization of $\varepsilon$-CL using $\mathrm{MeO}-\mathrm{PEG}-\mathrm{OH}$ showed that preferential PCL propagation over the MeO-PEG$\mathrm{OH}$ initiation of the $\varepsilon$-CL $\left(k_{\mathrm{i}} \ll k_{\mathrm{p}}\right)$ occurred, leading to the low conversion of the macroinitiator. ${ }^{10}$ In addition, the reactivity of the carboxylic acid group toward the lipase is known to be significantly lower than that of $\varepsilon-\mathrm{CL},{ }^{11} v i z$., the formation of the lipase-activated HOOC-PEG derivatives is not considered $\left(k_{\mathrm{e}} \ll\right.$ $\left.k_{\mathrm{em}}\right)$. In other words, the esterification of the PEG-terminal carboxylic acid group with either the propagation end of the hydroxyl group (PEG-PCL-OH) or PEG-OH macroinitiator was also limited, leading to the selective formation of the carboxylic acid end-

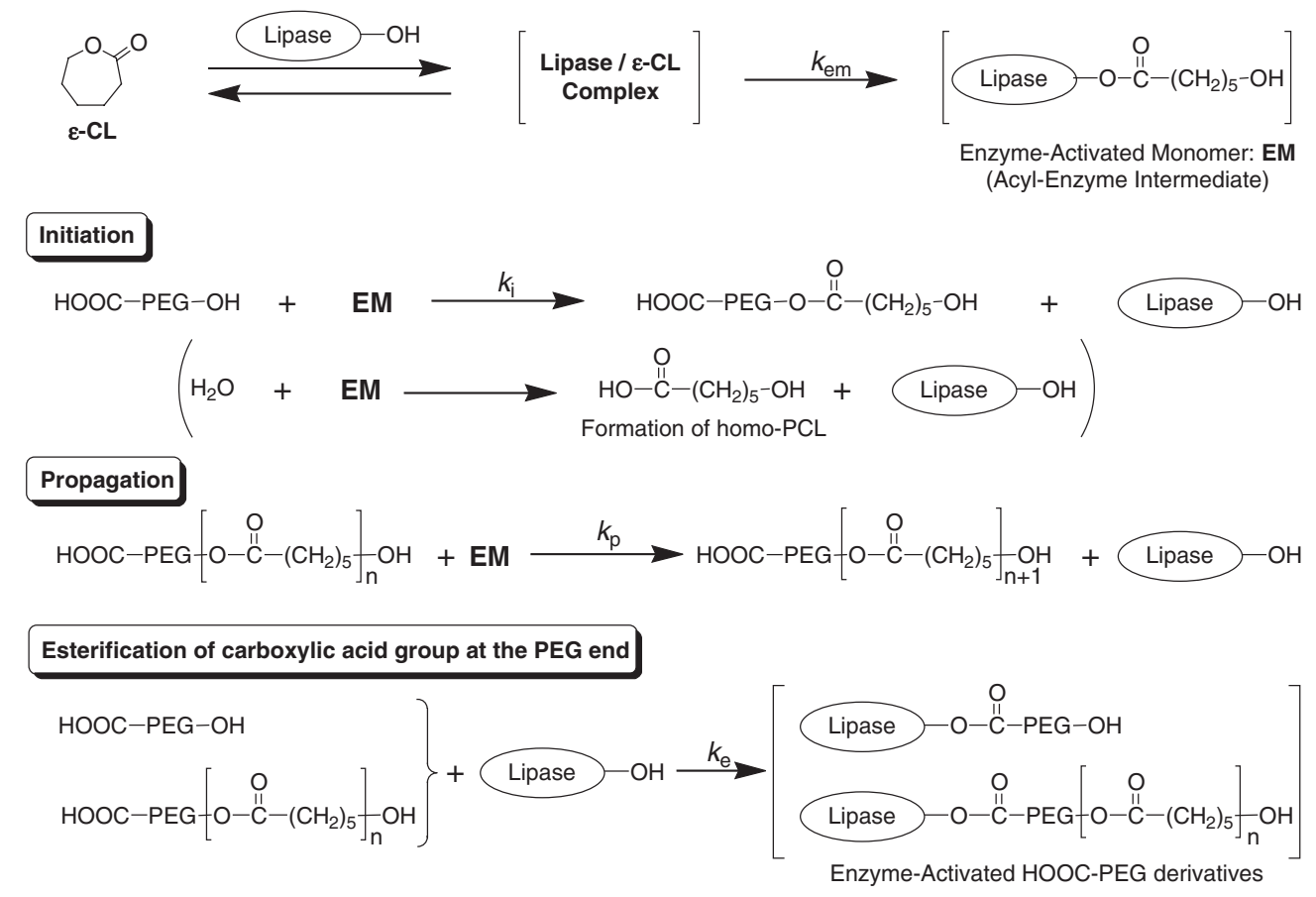

Scheme 2. Plausible mechanism of the lipase-catalyzed polymerization of $\varepsilon$-CL using HOOC-PEG-OH. 
functionalized PEG- $b$-PCL copolymer.

In conclusion, a novel synthetic rout to a carboxylic acid end-functionalized PEG- $b$-PCL copolymer is described here based on the lipase-catalyzed polymerization of $\varepsilon$-CL using an $\alpha$-carboxylic acid- $\omega$ hydroxy-PEG as a macroinitiator. Furthermore, the PEG- $b$-PCL micelles had a negative zeta potential, indicating that reactive carboxylic acid groups were located on the surface of the PEG- $b$-PCL micelles. Therefore, this reactive PEG- $b$-PCL micelle may have potential uses in the field of drug delivery systems as a targetable drug carrier.

Acknowledgment. This work was partially supported by the "Promotion of Creative Interdisciplinary of Materials Science for Novel Functions" program of the $21^{\text {st }}$ century Center of Excellence $(\mathrm{COE})$ program of the Ministry of Education, Culture, Sports, Science and Technology, Japan.

\section{REFERENCES}

1. a) H. Otsuka, Y. Nagasaki, and K. Kataoka, Adv. Drug Deliv. Rev., 55, 403 (2003).

b) K. Kataoka, A. Harada, and Y. Nagasaki, Adv. Drug Deliv. Rev., 47, 113 (2001). c) G. S. Kwon and K. Kataoka, Adv. Drug Deliv. Rev., 16, 295 (1995).

2. J. Z. Bei, J. M. Li, Z. F. Wang, J. C. Le, and S. G. Wang, Polym. Adv. Technol., 8, 963 (1997).

3. a) M. L. Forrest, C.-Y. Won, A. W. Malick, and G. S. Kwon, J. Controlled Release, 110, 370 (2006).

b) C. Allen, J. Han, Y. Yu, D. Maysinger, and A. Eisenberg, J. Controlled Release, 63, 275 (2000).

c) C. Allen, Y. Yu, D. Maysinger, and A. Eisenberg, Bioconjugate Chem., 9, 564 (1998).

4. L. Luo, J. Tam, D. Maysinger, and A. Eisenberg, Bioconjugate Chem., 13, 1295 (2002).

5. F. He, S. Li, M. Vert, and R. Zhuo, Polymer, 44, 5145 (2003).

6. M. Yokoyama, T. Okano, Y. Sakurai, A. Kikuchi, N. Ohsako,Y. Nagasaki, and K. Kataoka, Bioconjugate Chem., 3, 275 (1992)

7. T. Ishii, M. Yamada, H. Hirase, and Y. Nagasaki, Polym. J., 37, 221 (2005).

8. C. Hedfors, E. Ostmark, E. Malmstrom, K. Hult, and M. Martinelle, Macromolecules, 38, 647 (2005).

9. H. Uyama, K. Takeya, and S. Kobayashi, Bull. Chem. Soc. Jpn., 68, 56 (1995).

10. A. A. Panova and D. Kaplan, Biotechnol. Bioeng., 84, 103 (2003).

11. S. Kobayashi, H. Uyama, and S. Kimura, Chem. Rev., 101, 3793 (2001). 